\title{
A Newly Developed Wrought Ni-Fe-Cr-based Superalloy for Advanced Ultra-Supercritical Power Plant Applications Beyond $700{ }^{\circ} \mathrm{C}$
}

\author{
Shuai Guan ${ }^{1}$ Chuan-Yong Cui ${ }^{1}$
}

Received: 11 May 2015/Revised: 25 June 2015/Published online: 21 July 2015

(c) The Chinese Society for Metals and Springer-Verlag Berlin Heidelberg 2015

\begin{abstract}
Some existing wrought $\mathrm{Ni}-\mathrm{Cr}-\mathrm{Co}$-based superalloys are being evaluated as the candidate materials for advanced ultra-supercritical power plant applications beyond $700{ }^{\circ} \mathrm{C}$ due to their high creep strength. But they are all prohibitively expensive due to the addition of $\mathrm{Co}$, Mo and $\mathrm{W}$. Here we developed a new Ni-Fe-Cr-based superalloy (named as HT700 alloy) with low cost and high strength. This paper reports the mechanical properties and fracture modes of HT700 alloy to support its high temperature applications and to understand prospective failure mechanism. Fractographic examinations indicate that the fracture modes shift with test condition change. In addition, the HT700 alloy has relatively stable microstructure at $750{ }^{\circ} \mathrm{C}$. Compared with IN740 and GH2984 alloys, this new alloy has higher yield strength in the temperature range from room temperature to $800{ }^{\circ} \mathrm{C}$. The creep life of this new alloy is much longer than that of the Ni-Fe-based superalloy GH2984. The results suggest that this new alloy is a promising material for advanced ultra-supercritical power plant applications beyond $700{ }^{\circ} \mathrm{C}$.
\end{abstract}

KEY WORDS: Wrought Ni-Fe-Cr-based superalloy; Low cost; High strength; Fracture mode

\section{Introduction}

In the twenty-first century, the world faces the critical challenge of providing abundant and cheap electricity to meet the needs of growing global population while at the same time preserving environmental values [1]. But traditional methods of coal combustion emit environmental pollutants and $\mathrm{CO}_{2}$ (approximately 10 billion tons per year) at high levels compared to other energy generation options [1-3]. Therefore, the requirements for higher efficiency, less energy consumption and reduced environmental impact are pushing fossil-fired power plants to advanced

Available online at http://link.springer.com/journal/40195

Chuan-Yong Cui

chycui@imr.ac.cn

1 Institute of Metal Research, Chinese Academy of Sciences, Shenyang 110016, China ultra-supercritical (A-USC) conditions with steam temperature of up to $700-760{ }^{\circ} \mathrm{C}$ and pressure of up to 35-37.5 MPa [4-7]. The key to higher operating temperatures and stresses in A-USC technology lies in the availability of appropriate materials with enhanced creep strength at intermediate temperature and with costs of manufacture and fabrication that will yield a cost of electricity acceptable to consumers [8]. The requirements imposed by these conditions are obviously beyond the temperature capacity of the presently widely used ferritic and austenitic steels for USC power plants, as steels are limited to temperature below $680{ }^{\circ} \mathrm{C}$ [5]. It is thus likely that nickel-based superalloys with higher temperature capacity will be needed, and some existing wrought $\mathrm{Ni}-$ Cr-Co-based superalloys such as IN740 [6], IN617 [5], Nimonic263 [9] are being evaluated as the candidate materials for USC. Despite of possessing excellent mechanical properties, they are all prohibitively expensive due to the addition of Co, Mo and W. Compared with those Ni-based superalloys, HR6W and GH2984 alloys have 
attracted much attention due to their low costs; however, it does not show high enough creep strength at high temperature of up to $700{ }^{\circ} \mathrm{C}$. Therefore, a new superalloy with combination of low cost and enhanced strength beyond $700{ }^{\circ} \mathrm{C}$ has to be used. In present study, a new wrought $\mathrm{Ni}-$ Fe-Cr-based superalloy (named as HT700 alloy) with improved strength beyond $700{ }^{\circ} \mathrm{C}$ and with low cost was successfully developed.

\section{Experimental}

The nominal chemical compositions (wt\%) of HT700 alloy are $\mathrm{Ni}-18 \mathrm{Cr}-2.8(\mathrm{~W}+\mathrm{Mo}+\mathrm{Nb})-2.4 \mathrm{Ti}-1.8 \mathrm{Al}-0.15 \mathrm{Si}-$ $0.5 \mathrm{Mn}-20 \mathrm{Fe}-0.06 \mathrm{C}-0.02 \mathrm{P}$. The $1.8 \% \mathrm{Al}$ in conjunction with $18 \% \mathrm{Cr}$ is for the consideration of good oxidation resistance at high temperatures beyond $700{ }^{\circ} \mathrm{C}$. Furthermore, the high contents of $\mathrm{Al}(1.8 \%)$ and $\mathrm{Ti}$ (2.4\%) are expected to produce enough $\gamma^{\prime}$ precipitates which are beneficial to the creep strength and the yield strength. The additions of $\mathrm{W}$ and Mo are for the consideration of solid solution strengthening. The addition of $0.02 \% \mathrm{P}$ is expected to increase the creep strength due to the enhancement of the grain boundary strength [10-14].

HT700 alloy was vacuum melted using high purity raw materials, homogenized at $1200{ }^{\circ} \mathrm{C}$ for $24 \mathrm{~h}$ and aircooled. Then, the ingot was forged into block at $1160{ }^{\circ} \mathrm{C}$. The HT700 alloy was aging heat treated at $750{ }^{\circ} \mathrm{C}$ for $16 \mathrm{~h}$ and then air-cooled. Tensile test specimens with $3 \mathrm{~mm}$ in gauge diameter and $15 \mathrm{~mm}$ in gauge length were machined from as-aged samples and tested in the temperature range from room temperature to $800{ }^{\circ} \mathrm{C}$ with a strain rate of $3 \times 10^{-4} \mathrm{~s}^{-1}$. Tensile creep tests were carried on specimens with $5 \mathrm{~mm}$ in gauge diameter and $25 \mathrm{~mm}$ in gauge length at various conditions. The microstructure was analyzed by scanning electron microscopy (SEM) equipped with EDS and transmission electron microscopy (TEM). The $\gamma^{\prime}$ was examined before and after creep-rupture test by SEM. Thermal-calc software, of which the database is TTNi7, was used to calculate theoretically the total volume fraction of $\gamma^{\prime}$ in HT700 alloy.

\section{Results and Discussion}

The microstructure of HT700 alloy is shown in Fig. 1. The microstructure mainly consisted of $\gamma$ matrix, spherical $\gamma^{\prime}$ precipitates and carbides. Annealing twins in the $\gamma$ grains were also observed. Carbides distributed at the grain boundaries and within the grains. Energy Dispersive Spectroscopy (EDS) analysis of the carbides identified the carbides formed within the grains mainly as $M C$ type carbides, in which $\mathrm{M}$ is mostly substituted for $\mathrm{Nb}, \mathrm{Ti}$. The carbides observed at the grain boundaries are mainly $M_{23} \mathrm{C}_{6}$ type carbides in a form of ellipsoid (Fig. 1b), in which $M$ is mainly substituted for $\mathrm{Cr}$ and Fe. Although $0.02 \mathrm{wt} \%$ of phosphorus is contained in HT700 alloy, no phosphide was observed both by SEM and by TEM. At higher magnification, spherical $\gamma^{\prime}$ particles within the grains were observed. The total volume fraction of the $\gamma^{\prime}$ in HT700 alloy was nearly $20 \%$ according to theoretical calculation based on thermal-calc software. The total volume fraction of the $\gamma^{\prime}$ in HT700 alloy is about 15\% higher than that of GH2984 (about 6\%), which might result in higher creep strength.

The tensile stress-strain curves of HT700 alloy at room temperature, 700 , and $800{ }^{\circ} \mathrm{C}$ are shown in Fig. 2a. The tensile elongation of HT700 alloy at room temperature, $700,800{ }^{\circ} \mathrm{C}$ was $16.3 \%, 15.5 \%$, and $14.3 \%$, respectively.
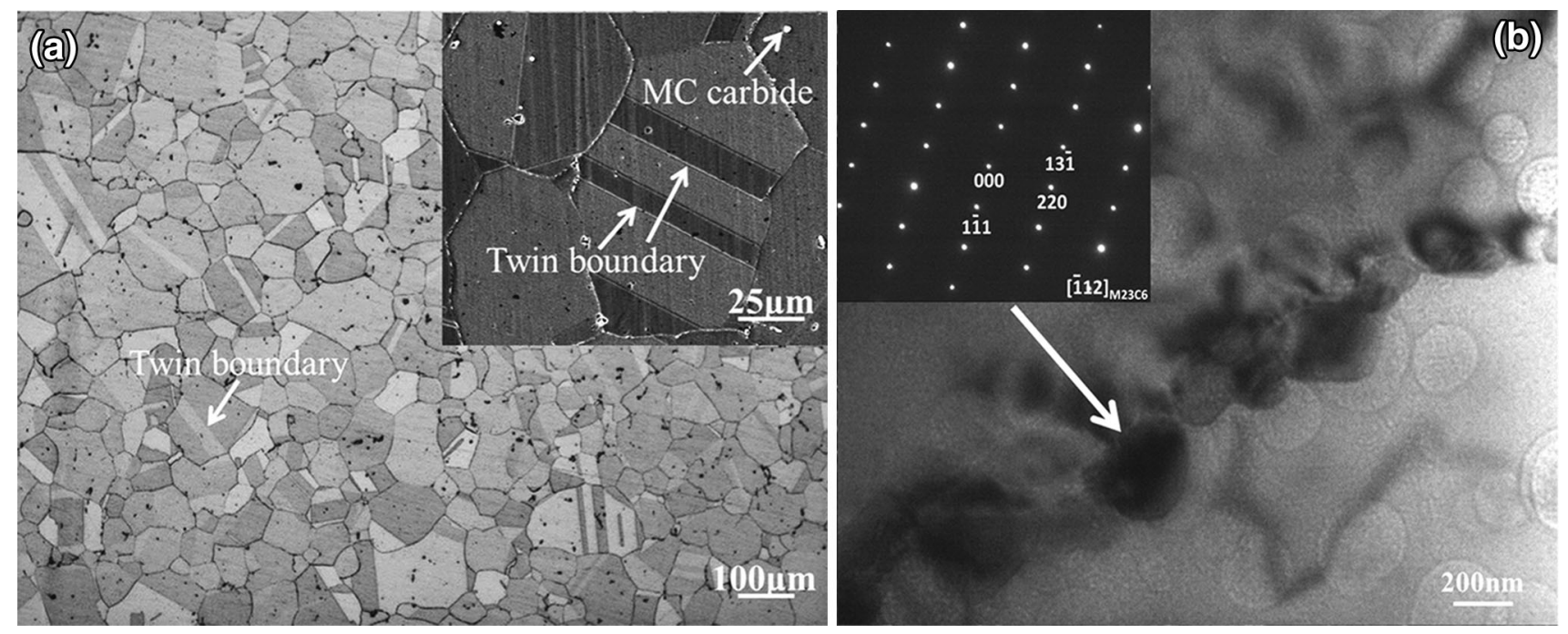

Fig. 1 a Image of the HT700 alloy illustrating twin boundaries and MC carbides within the grains, b TEM morphology and SAED pattern of grain boundary precipitation 

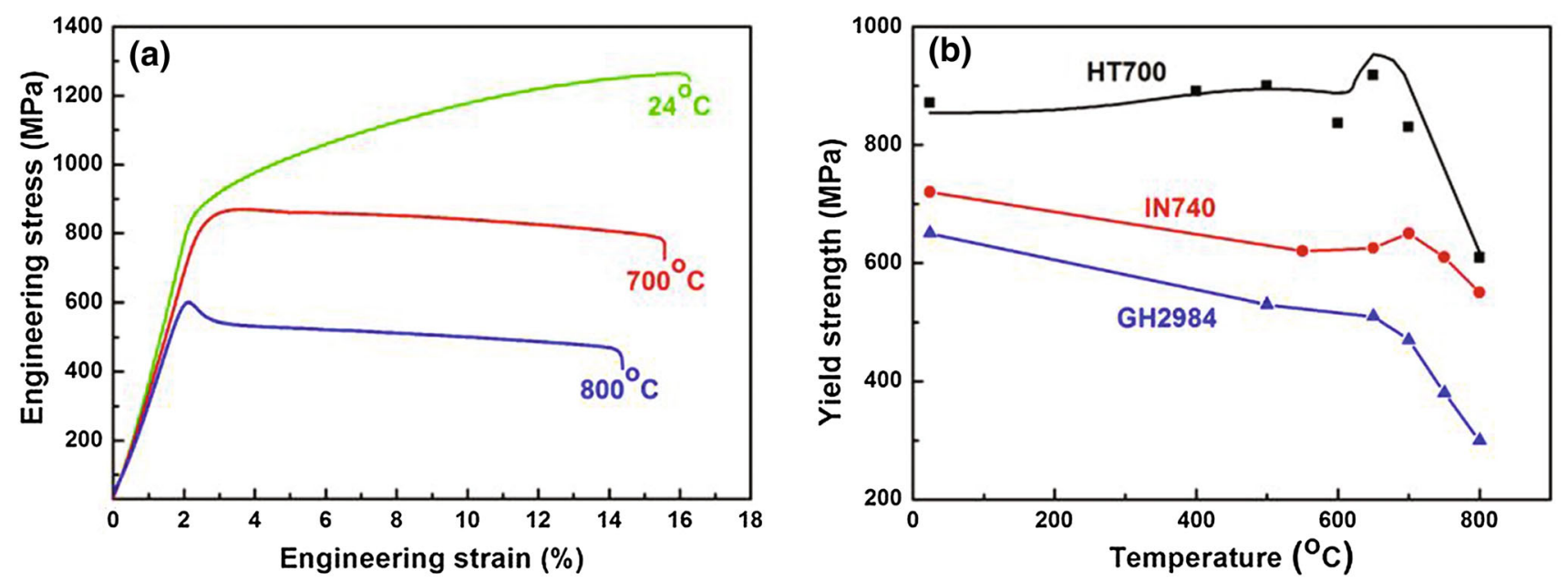

Fig. 2 a Tensile engineering stress strain curves of HT700 alloy tested at room temperature, 700 and $800{ }^{\circ} \mathrm{C}$, b comparison of tensile yield strength for HT700, IN740 and GH2984 alloys from room temperature to $800{ }^{\circ} \mathrm{C}$

The ductility just had a mild decrease in the $700-800{ }^{\circ} \mathrm{C}$ range of interest and the tensile ductility at the temperature range from 700 to $800{ }^{\circ} \mathrm{C}$ was comparable to that at room temperature. The yield strength (YS) of HT700 alloy as a function of temperature is shown in Fig. 2b. The YS of IN740 and GH2984 alloys tested at different temperatures, which was obtained from Ref. [15], is also shown in Fig. 2b. The YS of HT700 alloy remained relatively constant at the temperature range from room temperature to $600{ }^{\circ} \mathrm{C}$ and even showed a small maximum at the temperatures in the vicinity of $650{ }^{\circ} \mathrm{C}$ and then decreased sharply with the temperature increasing. It is widely accepted that the flow stress of the $\gamma^{\prime}$ precipitates increases with the temperature increasing, but the $\gamma^{\prime}$ precipitates will soften when the temperature is high enough. Therefore, the relatively stable YS of HT700 alloy from room temperature to $600{ }^{\circ} \mathrm{C}$ could be explained based on the fact that the softening of $\gamma$ matrix is compensated by the strengthening of $\gamma^{\prime}$ precipitates until about $600{ }^{\circ} \mathrm{C}$. With temperature increasing further, strengthening of $\gamma^{\prime}$ precipitates is just partly offset by the softening of $\gamma$ matrix and therefore the net effect will result in the YS of HT700 alloy increasing in the temperature range from 600 to $650{ }^{\circ} \mathrm{C}$ and even reaching the maximum at about $650{ }^{\circ} \mathrm{C}$. However, sufficient thermal activation at high temperatures will lead to the softening of $\gamma^{\prime}$ precipitates and therefore the strength decrease in both $\gamma$ matrix and $\gamma^{\prime}$ precipitates would result in the YS of HT700 alloy decreasing sharply in the temperature range from 650 to $800{ }^{\circ} \mathrm{C}$. Compared with IN740 and GH2984 alloys, HT700 alloy had higher YS in the temperature range from room temperature to $800{ }^{\circ} \mathrm{C}$. During $650-800{ }^{\circ} \mathrm{C}$, the YS of HT700 alloy decreased sharply with the temperature increasing, resulting in the YS intervals between HT700 alloy and IN740 alloy to become increasingly narrow, but were still 300-400 MPa higher than that of GH2984. This may be attributed to the fact that HT700 alloy has higher $\gamma^{\prime}$ content (about 20\%) and finer grain size $(56 \mu \mathrm{m})$ than that of GH2984 alloy. The microstructural parameters of GH2984 and IN740 were obtained from Refs. [6, 13, 16, 17], as shown in Table 1.

The fracture surfaces for the tensile tests subjected to different temperatures were examined by SEM. The fracture surfaces obtained at room temperature and $700{ }^{\circ} \mathrm{C}$ were selected to show the fracture transformation with test conditions changing, as shown in Fig. 3. Tensile specimen had a transgranular failure mode at room temperature, as clearly illustrated in Fig. 3a, b. The fracture surface obtained at $700{ }^{\circ} \mathrm{C}$ was similar to the fracture surface obtained at room temperature, but had a small portion of intergranular area on the edge of the tensile specimen. And secondary grain boundary cracking could be detected on the intergranular area, which demonstrates the grain boundary adhesion decreases when the temperature is high enough. It is worth noting that the intergranular area just occupied a small fraction of the entire fracture surface, demonstrating HT700 alloy still possesses relatively good grain boundary strength at $700{ }^{\circ} \mathrm{C}$.

Creep curves of HT700 alloy tested at $750{ }^{\circ} \mathrm{C}$ and $200 \mathrm{MPa}$, at $750{ }^{\circ} \mathrm{C}$ and $250 \mathrm{MPa}$ and at $800{ }^{\circ} \mathrm{C}$ and $200 \mathrm{MPa}$ are shown in Fig. 4a. Creep curves tested at $750{ }^{\circ} \mathrm{C}$ and $250 \mathrm{MPa}$ and at $800{ }^{\circ} \mathrm{C}$ and $200 \mathrm{MPa}$ showed

Table 1 Microstructural parameters of HT700, GH2984 and IN740 alloys

\begin{tabular}{llcc}
\hline & $\begin{array}{l}\text { Content of } \mathrm{Al}+\mathrm{Ti} \\
(\text { wt.\% })\end{array}$ & $\begin{array}{l}\text { Grain size } \\
(\mu \mathrm{m})\end{array}$ & $\begin{array}{l}\gamma^{\prime} \text { content } \\
(\%)\end{array}$ \\
\hline HT700 & 4.2 & 56 & 20 \\
GH2984 & $1.1-1.7$ & 65 & 6 \\
IN740 & $2.3-2.7$ & 200 & 13 \\
\hline
\end{tabular}



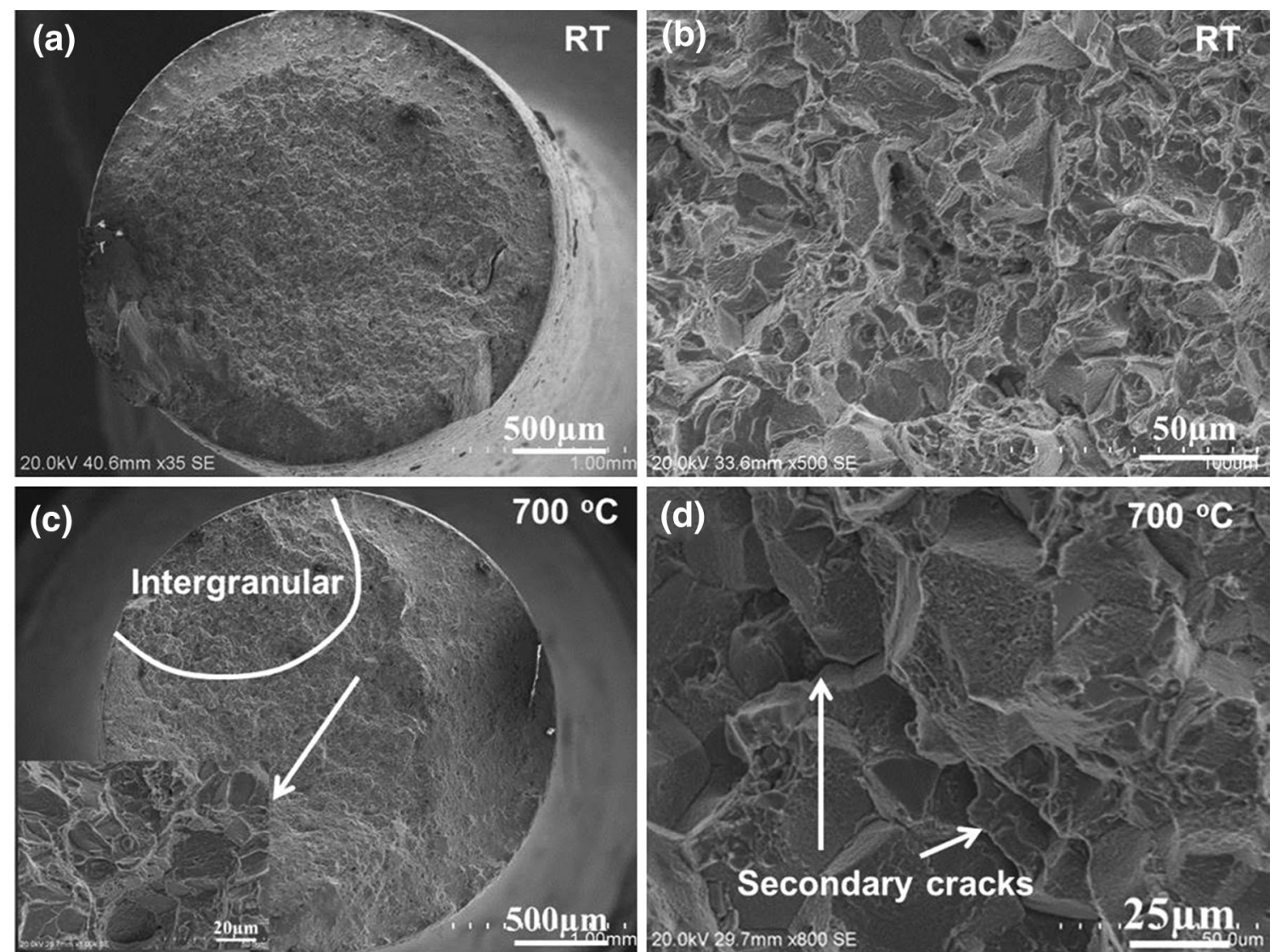

Fig. 3 Typical fracture surfaces for tensile tests at room temperature $\mathbf{a}, \mathbf{b}, 700{ }^{\circ} \mathrm{C} \mathbf{c}, \mathbf{d}$. Note the fracture surface transformed from transgranular (room temperature) to predominantly transgranular but with small range intergranular area with grain boundary cracking

the same tendency with a short primary creep stage followed by a relatively little steady-state condition and then a very extended accelerating stage leading to failure. Creep curve tested at $750{ }^{\circ} \mathrm{C}$ and $200 \mathrm{MPa}$ showed a relatively longer steady-state condition, and therefore creep-rupture life at $750{ }^{\circ} \mathrm{C}$ and $200 \mathrm{MPa}$ was longer (about $940 \mathrm{~h}$ ). The Larson-Miller parameter (LMP) plot of GH2984 alloy which was obtained from Ref. [15] and that of HT700 are shown in Fig. $4 b$, which shows the creep resistance of HT700 alloy is much better than that of GH2984 alloy.
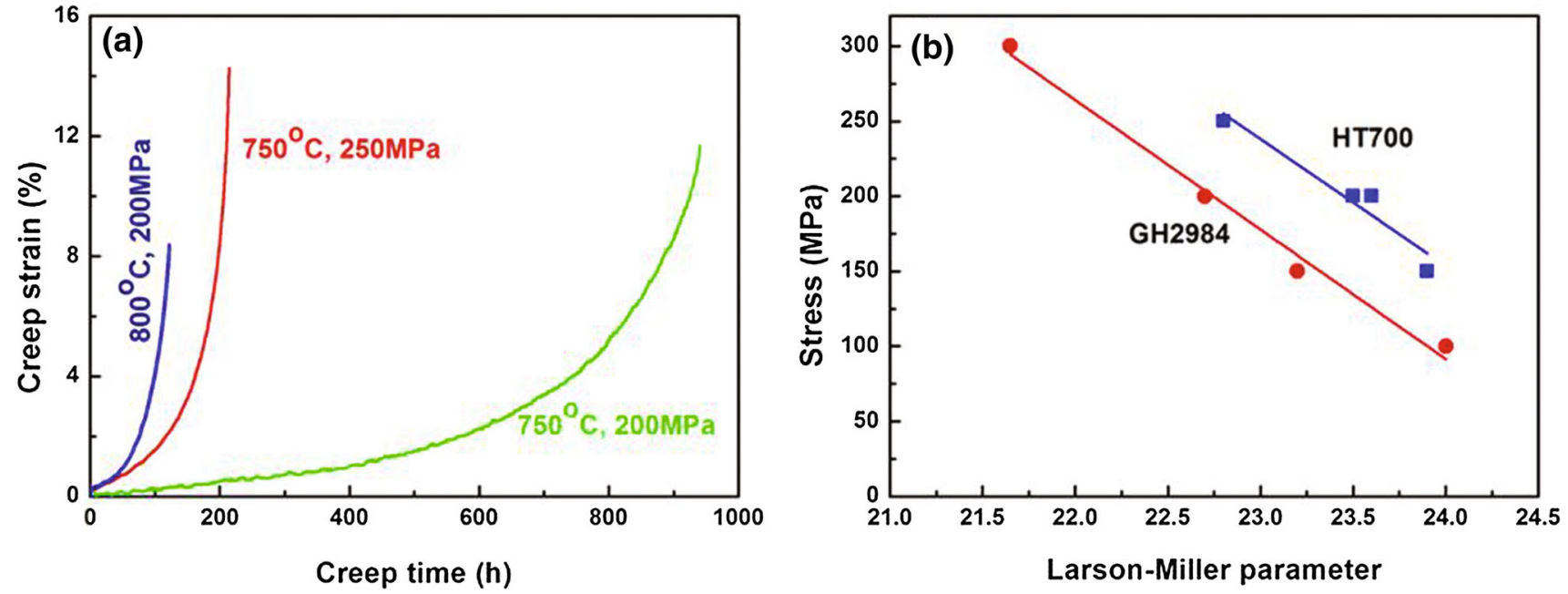

Fig. 4 a Creep curves of $\mathrm{HT} 700$ alloy tested at $750{ }^{\circ} \mathrm{C}$ and $200 \mathrm{MPa}$, at $750{ }^{\circ} \mathrm{C}$ and $250 \mathrm{MPa}$ and at $800{ }^{\circ} \mathrm{C}$ and $200 \mathrm{MPa}$; b LMP of $\mathrm{HT} 700$ alloy plotted as a function of stress, together with that of GH2984 alloy 
Table 2 Creep life and elongation of HT700 alloy tested at various conditions

\begin{tabular}{lll}
\hline Condition & Life (h) & Elongation (\%) \\
\hline $750{ }^{\circ} \mathrm{C} / 200 \mathrm{MPa}$ & 940 & 12 \\
$750{ }^{\circ} \mathrm{C} / 250 \mathrm{MPa}$ & 215 & 16 \\
$800{ }^{\circ} \mathrm{C} / 150 \mathrm{MPa}$ & 192 & 18 \\
$800{ }^{\circ} \mathrm{C} / 200 \mathrm{MPa}$ & 122 & 10 \\
\hline
\end{tabular}

Creep life and elongation of HT700 alloy tested at various conditions are listed in Table 2. Creep life decreased with increasing test temperature and applied stress level. For example, creep life of HT700 alloy decreased from 940 to $122 \mathrm{~h}$ when the temperature increased from 750 to $800{ }^{\circ} \mathrm{C}$. At $750{ }^{\circ} \mathrm{C}$, the creep life dropped from 940 to $215 \mathrm{~h}$ when the applied stress increased from 200 to $250 \mathrm{MPa}$. It is worth noting that creep-rupture life of HT700 alloy tested at $750{ }^{\circ} \mathrm{C}$ and $200 \mathrm{MPa}$ was still two times longer than that of GH2984 alloy (444 h) tested at $750{ }^{\circ} \mathrm{C}$ and $150 \mathrm{MPa}$ [15]. The longer creep-rupture life of HT700 alloy may be attributed to higher content of $\gamma^{\prime}(20 \%)$ and the addition of trace $\mathrm{P}$ as grain boundary enhancement element. Although phosphorus has normally been regarded as a detrimental element in the cast superalloys, it draws attention in recent years that moderate addition of phosphorus as an alloying element could markedly prolong the creep life for some wrought superalloys such as GH761 [18, 19], IN718 [11, 12] and GH2984 [13]. Most researchers attributed the improvement in the creep life to the strengthened grain boundaries caused by phosphorus segregation on the grain boundaries which has already been confirmed by atom probe tomography [20]. So it is logical to deduce that phosphorus also segregates on the grain boundaries and strengthens the grain boundaries in HT700 alloy, thus prolonging the creep life of HT700 alloy. It must be also noted that HT700 alloy has relatively lower content of W (1 wt $\%$ ) as compared with GH2984 alloy ( 2 wt \% W). W is generally regarded as a typical solid solution element and decreases the stacking fault energy (SFE) in the superalloys, thus improving creep properties of superalloys. Obviously, however, the decrease in creep life due to less W content in HT700 alloy is not able to contend with the
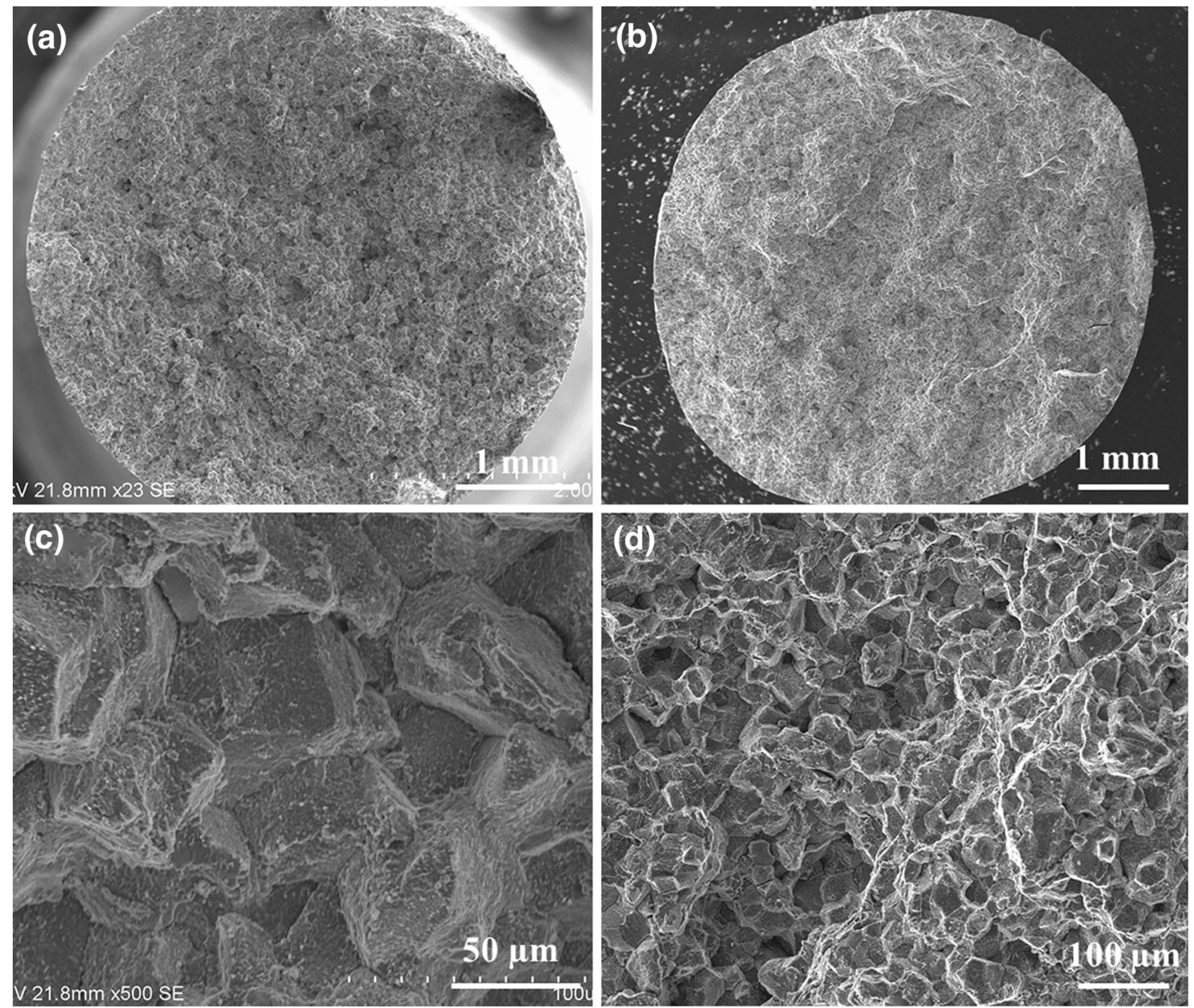

Fig. 5 Typical fracture surfaces of the alloy crept at $750{ }^{\circ} \mathrm{C} / 200 \mathrm{MPa} \mathbf{a}, \mathbf{c}, 750{ }^{\circ} \mathrm{C} / 250 \mathrm{MPa} \mathbf{b}, \mathbf{d}$ 

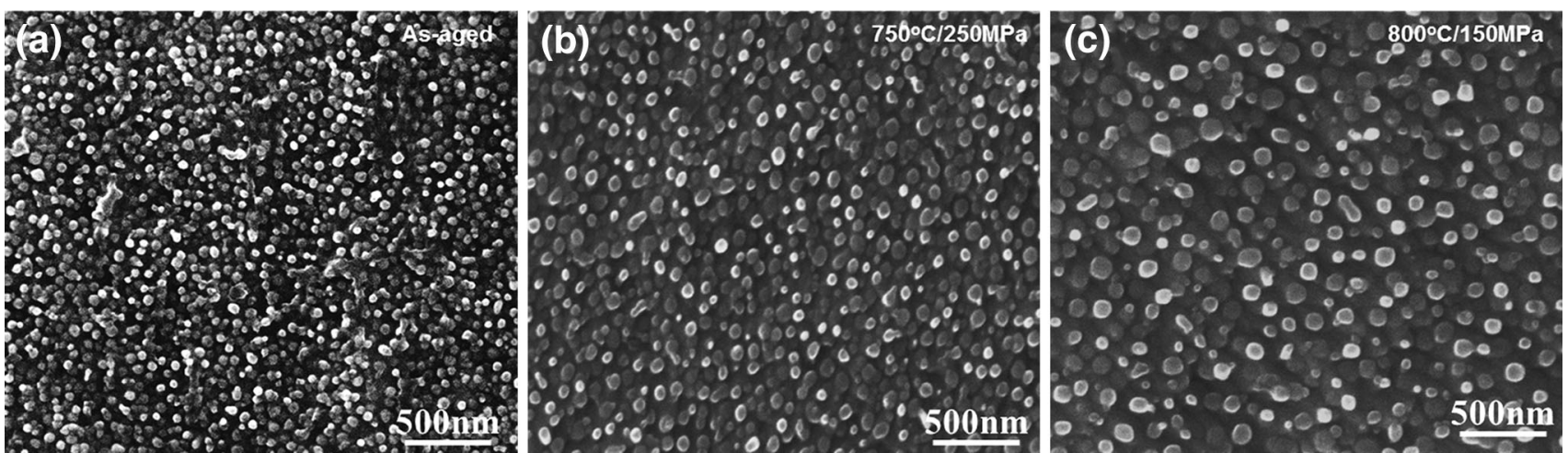

Fig. 6 Typical $\gamma^{\prime}$ phase of as-aged HT700 alloy a, HT700 alloy b after creep rupture tested at $750{ }^{\circ} \mathrm{C} / 250 \mathrm{MPa}$, c HT700 alloy after creep rupture tested at $800{ }^{\circ} \mathrm{C} / 150 \mathrm{MPa}$

increase in creep life caused by higher volume fraction of $\gamma^{\prime}(20 \%)$ and the addition of trace $\mathrm{P}$ as grain boundary enhancement element.

Figure 5 shows typical creep fracture surfaces tested at $750{ }^{\circ} \mathrm{C}$ and $200 \mathrm{MPa}$ and at $750{ }^{\circ} \mathrm{C}$ and $250 \mathrm{MPa}$. Creep specimens failed in an intergranular mode, which are different from tensile fracture mode. The appearance of fracture surface became rougher when the applied stress level increased, clearly shown in Fig. 5a and b, because the increased stress level would lead to more grain boundary cracks, thus leading to the linkage of cracks and consequently the fracture of the specimen.

The microstructure examinations of HT700 alloy before and after creep rupture by SEM showed that the $\gamma^{\prime}$ maintained its spherical morphology but coarsened during creep test. The size of $\gamma^{\prime}$ precipitates for as-aged HT700 alloy was less than $40 \mathrm{~nm}$, however lots of $\gamma^{\prime}$ precipitates reached $70 \mathrm{~nm}$ after creep rupture tested at $750{ }^{\circ} \mathrm{C}$ and $250 \mathrm{MPa}$ and $110 \mathrm{~nm}$ after creep rupture tested at $800^{\circ} \mathrm{C}$ and $150 \mathrm{MPa}$, as shown in Fig. 6. The creep life of HT700 alloy tested at $750{ }^{\circ} \mathrm{C}$ and $250 \mathrm{MPa}$ and at $800{ }^{\circ} \mathrm{C}$ and $150 \mathrm{MPa}$ was 215 and $192 \mathrm{~h}$, respectively. However, the size of $\gamma^{\prime}$ was much smaller after creep rupture tested at $750{ }^{\circ} \mathrm{C}$ and $250 \mathrm{MPa}$ than that after creep rupture tested at $800{ }^{\circ} \mathrm{C}$ and $150 \mathrm{MPa}$, demonstrating HT700 alloy has more stable microstructural stability at $750{ }^{\circ} \mathrm{C}$ than at $800{ }^{\circ} \mathrm{C}$.

\section{Summary}

A newly developed HT700 alloy has higher yield strength than GH2984 and IN740 alloys from room temperature to $800{ }^{\circ} \mathrm{C}$. The creep-rupture resistance of this new alloy is much better than that of the $\mathrm{Ni}-\mathrm{Fe}$-based superalloy GH2984 due to higher volume fraction of $\gamma^{\prime}$. Good mechanical properties beyond $700{ }^{\circ} \mathrm{C}$ combined with low cost make this new superalloy appropriate for advanced ultra-supercritical power plant applications beyond $700{ }^{\circ} \mathrm{C}$.
Acknowledgments This work was financially supported by the High Technology Research and Development Program of China (No. 2014AA041701) and the National Natural Science Foundation of China (Nos. 51171179, 51271174, 51331005, and 11332010).

\section{References}

[1] R. Viswanathan, J.F. Henry, J. Tanzosh, G. Stanko, J. Shingledecker, B. Vitalis, R. Purgert, J. Mater. Eng. Perform. 14, 281 (2005)

[2] G. Stein-Brzozowska, D.M. Flórez, J. Maier, G. Scheffknecht, Fuel 108, 521 (2013)

[3] X.W. Cui, J.L. Hong, M.M. Cao, Energy 45, 952 (2012)

[4] P.D. Jablonski, J.A. Hawk, C.J. Cowen, P.J. Maziasz, JOM 64, 271 (2012)

[5] Q.Y. Wu, S. Hyojin, R.W. Swindeman, J.P. Shingledecker, V.K. Vasudevan, Metall. Mater. Trans. A 39, 2569 (2008)

[6] N.D. Evans, P.J. Maziasz, R.W. Swindeman, G.D. Smith, Scr. Mater. 51, 503 (2004)

[7] S.Q. Zhao, X.S. Xie, G.D. Smith, S.J. Patel, Mater. Sci. Eng. A 355, 96 (2003)

[8] T.B. Gibbons, Trans. Indian Inst. Met. 66, 631 (2013)

[9] M. Maldini, G. Angella, V. Lupinc, Mater. Sci. Eng. A 462, 436 (2007)

[10] N. Li, W.R. Sun, Y. Xu, S.R. Guo, D.Z. Lu, Z.Q. Hu, Mater. Lett. 60, 17 (2006)

[11] X.B. Liu, J.X. Dong, B. Tang, Y.H. Hu, X.S. Xie, Mater. Sci. Eng. A 270, 190 (1999)

[12] W.R. Sun, S.R. Guo, J.H. Lee, N.K. Park, Y.S. Yoo, S.J. Choe, Z.Q. Hu, Mater. Sci. Eng. A 247, 173 (1998)

[13] X. Xiao, H.Q. Zhao, C.S. Wang, Y.A. Guo, J.T. Guo, L.Z. Zhou, Acta Metall. Sin. 49, 421 (2013). (in Chinese)

[14] C.G. Mckamey, C.A. Carmichael, W.D. Cao, R.L. Kennedy, Scr. Mater. 38, 485 (1998)

[15] Z.H. Zhong, Y.F. Gu, Y. Yuan, Z. Shi, Mater. Lett. 109, 38 (2013)

[16] J.T. Guo, X.K. Du, Acta Metall. Sin. 41, 1221 (2005). (in Chinese)

[17] S.Q. Zhao, X.S. Xie, G.D. Smith, S.J. Patel, Mater. Des. 27, $1120(2006)$

[18] W.R. Sun, S.R. Guo, D.Z. Lu, Z.Q. Hu, Metall. Mater. Trans. A 28, 649 (1997)

[19] S.L. Yang, W.R. Sun, J.X. Wang, K.L. Wang, S.R. Guo, Z.Q. $\mathrm{Hu}$, Acta Metall. Sin. 45, 815 (2009). (in Chinese)

[20] T. Alam, P.J. Felfer, M. Chaturvedi, L.T. Stephenson, M.R. Kilburn, J.M. Cairney, Metall. Mater. Trans. A 43, 2183 (2012) 